SISTEMA
ELETRONIICO
DE REVISTAS
SER I UfPR

\title{
A produção da agricultura familiar atingida pela mineração na Região Central de Minas Gerais e os (des)caminhos do desenvolvimento rural em bases familiares
}

\section{The production of family agriculture affected by mining in the Central Region of Minas Gerais and the wrong paths of rural development on a family farming basis}

\author{
Viviane Guimarães PEREIRA ${ }^{1 *}$, Tayrine Parreira BRITO¹, Gabriela BELLEZE ${ }^{1}$, Kalahan de Mello \\ BATTISTON $^{1}$ \\ ${ }^{1}$ Universidade Federal de Itajubá (UNIFEI), Itajubá, MG, Brasil. \\ *E-mail de contato: vgpereira@yahoo.com.br
}

Artigo recebido em 6 de outubro de 2018, versão final aceita em 14 de novembro de 2019, publicado em 8 de maio de 2020.

RESUMO: $\quad$ O presente artigo busca analisar a importância da produção material da agricultura familiar na região central de Minas Gerais, nos municípios de Conceição do Mato Dentro, Alvorada de Minas e Dom Joaquim, e como o projeto minerário "Minas Rio", levado a cabo pela multinacional Anglo American desde 2008, compromete a disponibilidade de recursos das comunidades atingidas, interferindo nos processos de desenvolvimento rural em bases familiares. Este trabalho é resultado de pesquisa interdisciplinar desenvolvida entre 2015 e 2016 que teve como objetivo assessorar entidade de apoio à agricultura familiar na região a partir da caracterização das comunidades atingidas. As coletas de dados foram realizadas por meio de entrevistas realizadas nas unidades de produção familiares, bem como de agentes de desenvolvimento rural nos três municípios pesquisados. $\mathrm{O}$ conjunto de resultados encontrados mostrou que apesar da região ser caracterizada pela presença marcante da agricultura familiar, com potencial para alavancar o desenvolvimento em bases sustentáveis, através de produção rica e processos de beneficiamento tradicionais, o projeto minerário na região afetou as famílias agricultoras no que toca ao acesso aos recursos naturais, sobretudo hídricos, bem como provocou um esvaziamento do campo, alterando drasticamente os rumos do desenvolvimento rural em bases sustentáveis e territoriais. Há, contudo, uma indicação no resultado do estudo de que as famílias desenvolvem estratégias e diversas maneiras de resistir e permanecer em suas terras.

Palavras-chave: desenvolvimento; agricultura familiar; ambiente; mineração.

Desenvolv. e Meio Ambiente usa uma Licença Creative Commons - Atribuição-NãoComercial-SemDerivações 4.0 Internacional 
ABSTRACT: This article aims to analyze the importance of the material production of family agriculture in the central region of Minas Gerais, in the municipalities of Conceição do Mato Dentro, Alvorada de Minas and Dom Joaquim, as well as the "Minas Rio" mining project, carried out by the multinational AngloAmerican since 2008 , compromises the availability of resources of affected communities, interfering in rural development processes performed on a family basis. This work is the result of interdisciplinary research developed between 2015 and 2016, whose objective was to advise the organization of support to family agriculture in the region based on the characterization of affected communities. Data were collected through interviews with family production units, as well as rural development agents in the three municipalities surveyed. The results showed that, although the region is characterized by the strong presence of family agriculture, with the potential to leverage development on a sustainable basis, through rich production and traditional beneficiation processes, the mining project in the region affected access to natural resources, especially water resources, as well as it caused rural flight, which drastically changed the course of rural development on a sustainable and territorial basis. There is, however, an indication in the outcome of the study that families develop strategies and various ways of resisting and remaining on their land.

Keywords: development; family farming; environment; mining.

\section{Introdução}

Este artigo consiste na caracterização da agricultura familiar na região dos municípios de Conceição do Mato Dentro, Alvorada de Minas e Dom Joaquim-MG, com relação às suas formas de produção material, e de como o atingimento destas comunidades rurais pelo projeto minerário "Minas-Rio", levado a cabo pela multinacional Anglo American, interfere negativamente na reprodução social das famílias agricultoras em seus territórios originais, comprometendo o desenvolvimento rural. Aborda-se aqui o potencial da agricultura familiar nestes municípios e os descaminhos do empreendimento minerário para o desenvolvimento rural na região. São, pois, estas famílias rurais, de bases tradicionais, e impactadas pelo empreendimento que o presente trabalho aborda.
Os resultados deste trabalho são frutos do projeto de pesquisa interdisciplinar intitulado Levantamento das potencialidades da agricultura familiar e agroecológica das comunidades rurais atingidas pela mineração, vinculado e financiado pela Cáritas Brasileira Regional Minas Gerais ${ }^{1}$, sendo realizado pelo Núcleo Travessia (Núcleo de Pesquisa, Extensão e Apoio ao Desenvolvimento Rural e Agricultura Familiar) da Universidade Federal de Itajubá (UNIFEI).

A região compreendida por Conceição do Mato Dentro, Alvorada de Minas e Dom Joaquim - MG localiza-se a aproximadamente $200 \mathrm{~km}$ de Belo Horizonte (Figura 1), sendo conhecida pelo potencial turístico advindo da Serra do Espinhaço e da Serra do Cipó, bem como pela produção de queijos minas artesanais do Serro. Atualmente, novos olhares se voltaram para a região devido

\footnotetext{
${ }^{1}$ A Cáritas Brasileira é uma entidade de promoção e atuação social que trabalha na defesa dos direitos humanos, da segurança alimentar e do desenvolvimento sustentável solidário. A Cáritas Brasileira, fundada em 12 de novembro de 1956, é uma das 164 organizações-membros da Rede Cáritas Internacional presentes no mundo. Mais informações em <http://caritas.org.br/>
} 
ao empreendimento Minas-Rio da empresa Anglo American de extração e transporte, via mineroduto, de minério de ferro para o porto em São João da Barra - RJ, para fins de exportação.

A base teórica que orienta este trabalho está assentada em autores clássicos como Chayanov e Wolf na abordagem sobre modos de vida e trabalho camponês, em autores brasileiros como Abramovay, Ortega, Martins, Carneiro, Woortmann e Delgado na teorização acerca do desenvolvimento rural, e também autores como Zhouri, Milanez e Acserald na abordagem territorial e mineração, entre outros que dão luz a essa temática.

Do ponto de vista metodológico o destaque é pela proposta interdisciplinar que se assegura, segundo Raynaut (2011), no cruzamento de olhares científicos distintos, uma vez que reúne diferentes campos disciplinares em torno de um objetivo

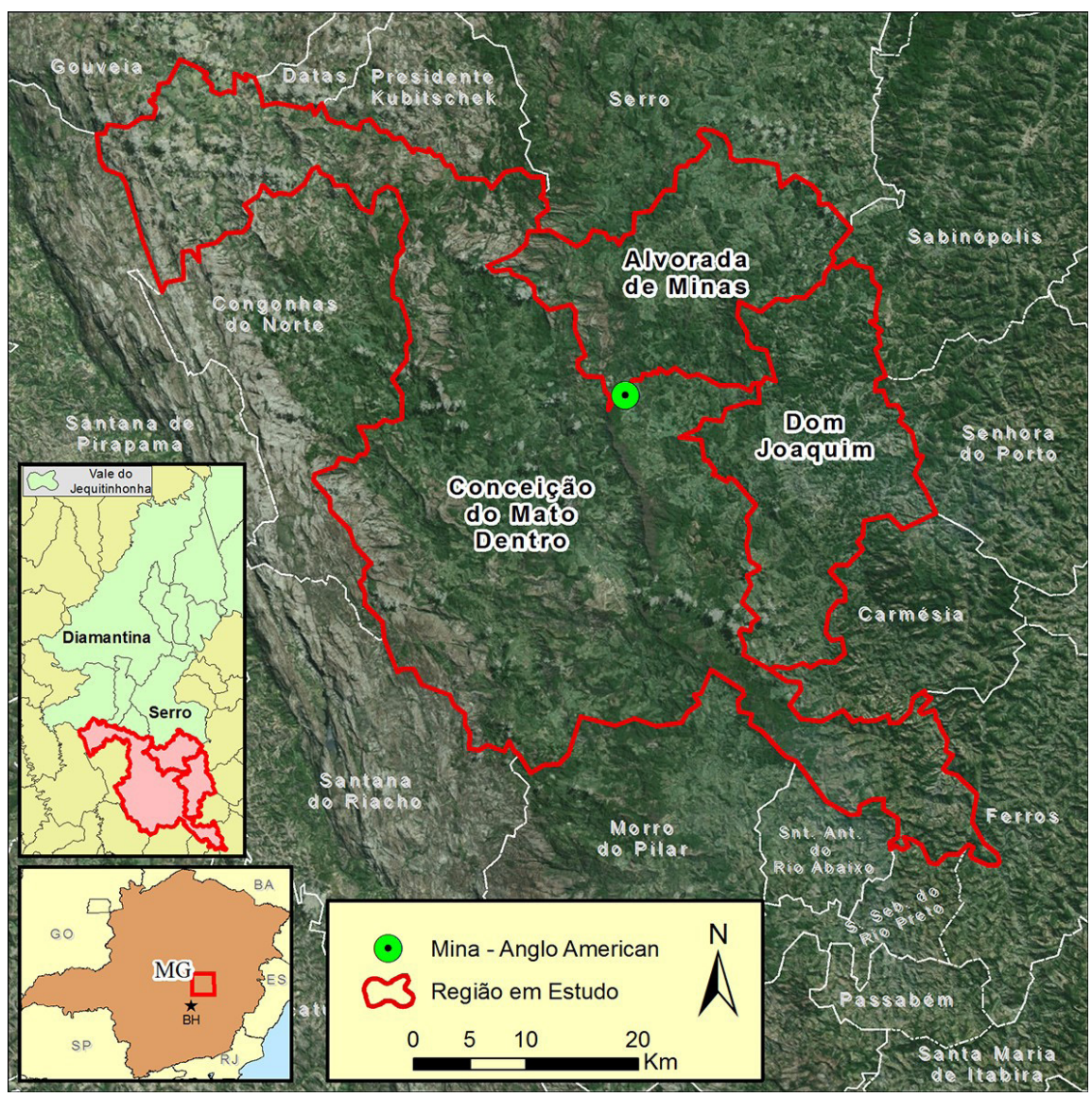

FIGURA 1 - Mapa da região estudada.

FONTE: Núcleo Travessia, 2016. 
comum. Neste artigo, este desafio metodológico se concretiza na medida em que pesquisadores de diversas formações se debruçam sobre um mesmo objetivo, em resposta à demanda social apresentada pela Cáritas Brasileira.

Este trabalho está dividido, além desta introdução nas discussões sobre: 2) agricultura familiar, território e políticas públicas de desenvolvimento rural; 3) os processos de desterritorialização provocados pelos grandes projetos de desenvolvimento; 4) o percurso metodológico da pesquisa; 5) o potencial da agricultura familiar da região; 6) os impactos da mineração sobre estas populações e, por fim, 7) conclusões.

\section{Agricultura familiar, território e políticas públicas de desenvolvimento rural}

Abordar conceitualmente o campesinato e a agricultura familiar no contexto da realidade brasileira tem sido motivo de intenso debate e questionamento quanto ao melhor termo para definir essa categoria social tão complexa. Há autores como Bruno (2016), Schneider \& Cassol (2017) e Wanderley (2017) que discutem a dicotomia entre agricultores familiares e camponeses, no entanto ambos concordam que embora existam agricultores considerados familiares fortemente integrados ao mercado, eles, no seu modo de vida, conservam elementos importantes de suas raízes camponesas.

O mais importante para este trabalho é revelar essa forma social, cujo papel da família é central na organização da produção e na constituição de seu modo de vida na terra. Para Lamarche (1993), as unidades familiares de exploração agrícola não podem ser definidas como um modo de produção específico, como se fossem um grupo social homogêneo, pois, mesmo tendo em comum a ligação estreita entre família e produção, a capacidade de se apropriarem dos meios de produção e desenvolvê-los é diversa. Essa diversidade tem a ver com as situações extremamente variadas em que vivem: histórias diferentes e contextos econômicos, sociais e políticos diversos. Por sua vez, elas possuem em comum a capacidade de se adaptarem a situações adversas e às mudanças no contexto, organizando suas estratégias de luta e sobrevivência, em função da memória que guardam de sua história e dos projetos que têm para o futuro, "a exploração familiar é ao mesmo tempo uma memória, uma situação, uma ambição e um desafio" (Lamarche, 1993, p. 22).

Nesse sentido, utilizou-se no presente trabalho as duas denominações, a agricultura familiar para descrever os aspectos produtivos e o campesinato na descrição dos costumes.

Ao propor pesquisar a importância da produção material da agricultura familiar em região atingida pela mineração, um outro tema importante emerge: a questão do território. Para debater o rural é necessário pensá-lo como um espaço, uma história, uma cultura, uma sociedade e inclusive uma economia, mas não simplesmente como um setor da economia. E neste sentido a noção de território é fundamental, pois amplia o olhar para além dos aspectos econômicos associados às atividades agropecuárias e incorpora a dimensão social e política que o envolve. Pensar o rural somente do ponto de vista econômico, ou setorial, apenas como espaço de produção de mercadorias, é uma análise parcial e sujeita a grandes equívocos.

A partir do começo dos anos 1970 cresceram as análises e interpretações sobre território e processos de territorialização; isso tem favorecido 
a compreensão dos espaços rurais na medida em que acrescenta variáveis ao olhar estritamente setorial, dando destaque aos sujeitos sociais e suas organizações e à maneira como os sujeitos utilizam os recursos em sua organização produtiva. Esses territórios são compreendidos como espaços geográficos, políticos, sociais e econômicos em que esses sujeitos sociais executam seus projetos de vida, realizando sua existência. É o lugar de gente, trabalho, organização política, produção, mercado e cultura (Pereira, 2013).

Nesse sentido há uma busca por construir uma concepção do desenvolvimento, com base na organização de interesses territorialmente delimitados, destacando a importância do "local" para o desenvolvimento.

Sobre a concepção de desenvolvimento existe uma disputa, com uma vertente que o concebe como a superação de algo que estaria atrasado, promovendo, de acordo com Furtado (1974) e Arrighi (1997), um discurso ilusório a serviço da manutenção da expansão capitalista. Furtado (1974) se utiliza da crítica à lei das vantagens comparativas, que embasou a doutrina liberal, para explicar o processo de divisão internacional do trabalho, em que os países subdesenvolvidos integram-se ao sistema capitalista internacional como exportadores de produtos primários, baseando-se no aumento das exportações e não no processo de acumulação e dos avanços tecnológicos. Furtado (2000) propõe uma nova reflexão sobre o desenvolvimento que se contraponha à doutrina liberal na crítica da teoria do comércio internacional e do sistema de divisão internacional do trabalho. Para ele a concepção de desenvolvimento não é alheia à estrutura social e deve levar em consideração, além da eficácia do sistema de produção, a satisfação das necessidades elementares da população.

O mesmo acontece na concepção do que é ou deveria ser o desenvolvimento rural, onde são apresentados de acordo com Delgado \& Bergamasco (2017, p. 65), dois projetos para o rural brasileiro, "por um lado, o projeto hegemônico, que se traduz pela modernização conservadora da agricultura, centrada na grande empresa agropecuária" e do outro lado "[...] um outro modelo de desenvolvimento que vem se consolidando no Brasil, cujos principais elementos são o reconhecimento de outras formas de agricultura e de vida no campo. Territorial e não setorial".

Em anos recentes o enfoque territorial foi usado na elaboração e implementação de políticas públicas de desenvolvimento rural, incorporando a noção de capital social e território em suas concepções. Mais especificamente a partir dos anos 1990, teve início uma mudança na ação do Estado brasileiro no estímulo ao desenvolvimento rural, e a agricultura familiar ganhou destaque nas políticas públicas brasileiras a partir desse período. Novos papéis foram atribuídos à agricultura e ao meio rural e houve uma incorporação, mesmo que parcial e incompleta, das demandas das populações rurais, através de um conjunto de políticas públicas que procuraram garantir seu fortalecimento econômico e social (Carneiro, 1997).

Nesse processo de revalorização do meio rural a abordagem territorial ganhou importância na formulação das políticas públicas brasileiras que foram sendo direcionadas aos territórios rurais a partir do começo dos anos 2000, reconhecendo-se a importância das diversidades territoriais para formulação de políticas de desenvolvimento. Assim também, as 
políticas de desenvolvimento rural passaram a dar maior ênfase ao caráter multifuncional das unidades rurais familiares (Ortega, 2008).

A negociação e a gestão de projetos territoriais foram dinamizadas pelos governos Lula (2003/2010), embora a proposta tenha surgido durante o governo anterior, passou a ser coordenada pela Secretaria de Desenvolvimento Territorial (SDT), ligada ao Ministério do Desenvolvimento Agrário $^{2}$, encarregada de implantar a abordagem territorial para o desenvolvimento rural. Essa negociação e gestão de projetos passaram pela interação entre a ação pública e ação coletiva dos rurais, através dos conselhos territoriais de desenvolvimento. Dessa forma, o MDA identificou e homologou cerca de 100 territórios prioritários, em apoio ao desenvolvimento rural e à agricultura familiar (Sabourin, 2009).

Segundo Abramovay $(2000 ; 2003)$, os projetos de desenvolvimento deveriam, a partir das concepções sobre território e capital social, ter como base uma rede de atores trabalhando para a valorização dos atributos de uma região (que não tem a ver com municipalidade), e, deveriam extrapolar um único setor profissional. Isso significou fortalecer o capital social dos territórios, muito mais do que promover o crescimento desta ou daquela atividade econômica, já que durante décadas, a prioridade dos programas de desenvolvimento para o mundo rural foi aprofundar a especialização de viés agropecuarista, sendo tratado como espaço econômico a ser integrado à indústria, através dos complexos agroindustriais (Delgado, 1985).

Nessa perspectiva territorial levada adiante pelo extinto MDA, o desenvolvimento rural dependeria da territorialidade e do capital social, na medida em que ampliaria o olhar para além dos aspectos econômicos e incorporaria a dimensão social e política e consideraria a importância da forma como os atores sociais se relacionam entre si, e que é relevante para os processos de desenvolvimento. Olhando por essa perspectiva, famílias e territórios estariam estreitamente ligados à dinâmica da reprodução social, considerando as unidades familiares em sua completude e as famílias vistas não apenas como unidades produtivas, mas como unidades sociais situadas num território com determinadas características socioeconômicas, culturais e ambientais.

Contudo, a construção das políticas de desenvolvimento rural em bases territoriais sofria com as contradições advindas das disputas por distintos projetos de desenvolvimento que se sobrepunham: se de um lado havia essa revalorização do rural e a viabilização de políticas públicas que buscavam dinamizar as sociedades rurais, por outro lado mantinha-se uma força contrária, baseada num modelo de desenvolvimento economicista, que historicamente priorizou a expansão de projetos de grande envergadura e impactos sociais e ambientais, como hidrelétricas, rodovias, planos de colonização, mineração e monoculturas e expropriou comunida-

\footnotetext{
${ }^{2}$ Em 2016, através da Medida Provisória $\mathrm{n}^{\mathrm{o}}$ 726, de 12 de maio de 2016, foram revogados os dispositivos da Lei $\mathrm{n}^{\circ} 10.683$, de 28 de maio de 2003, que dispunha sobre a organização da Presidência da República e dos Ministérios, extinguindo o MDA. Através do Decreto nº 8.780, de 27 de maio de 2016, as competências do MDA passaram para a Secretaria Especial de Agricultura Familiar e do Desenvolvimento Agrário, ligados à Casa Civil da Presidência da República, ou seja, o Ministério reduziu-se à Secretaria.
} 
des rurais de seus territórios de vida e de trabalho3. Esses projetos, que fazem parte da infraestrutura básica para o crescimento da economia, não têm como destinatários os grupos locais, que são na sua maioria populações camponesas; ao contrário, as retiram de seus lugares de origem (Martins, 1993; Zhouri \& Oliveira, 2005; Thomas Júnior, 2010; Pereira, 2013).

Quando populações rurais enfrentam dificuldades para produzir, originadas da degradação dos recursos naturais, resultantes das ações de empresas que se estabelecem em seus territórios, veem sua paisagem original se perder ao longo do processo e também seus canais de circulação do saber se partir. Isso exige deles um trabalho de reconstrução de referências na empreitada para se organizarem novamente, tanto produtivamente quanto socialmente.

\section{A desterritorialização e os conflitos provocados pelos grandes projetos}

A desterritorialização está relacionada às perdas de referenciais espaciais concretas, mas também culturais e simbólicas. Supõe a exclusão de determinado grupo de certa área que se apropriava, provocando a mobilidade forçada de pessoas, bens materiais e saberes, com ruptura da vida cotidiana do grupo social. Assim, se o território é o enraizamento, a localização e a referência, a desterritorialização é o fluxo, a deslocalização, o rompimento de fronteiras e de relações.

Quando ocorre a instalação e operação de grandes projetos de desenvolvimento num território que já era apropriado por outros grupos sociais, os quais utilizavam-se dos recursos naturais disponíveis, passa a ocorrer a disputa por tais recursos ou ainda a interrupção de atividades já praticadas devido aos impactos indesejáveis decorrentes das atividades do novo empreendimento, de modo a evidenciar um confronto de diferentes interesses e demonstrar "que estes conflitos não são consequências espontâneas dos processos de exploração dos recursos naturais, mas produzidos a partir das diferentes formas de apropriação do meio que são mediadas pelas relações desiguais de poder" (Souza \& Milanez, 2015, p. 6816). Essas disputas territoriais, ou também chamados conflitos socioambientais, muitas vezes se traduzem em longos embates e negociações, podendo inclusive chegar a confrontos violentos. Para Acserald (2010), os conflitos ambientais revelam que o ambiente de alguns sujeitos sociais prevalece sobre o de outros.

O campesinato brasileiro é marcado pela busca da construção de seus territórios, como lugar de vida, baú da memória familiar, reproduzível para gerações posteriores. Mas, a busca desse objetivo se deparou historicamente com uma mobilidade constante, fruto da pressão exercida diretamente sobre eles. O objetivo de construírem seus territórios sempre foi marcado pela luta contra a exploração e a expropriação produzida no desenvolvimento do capitalismo.

Essas expropriações acontecem em detrimento do uso de territórios para projetos econômicos de grande envergadura, como por exemplo, hidrelétricas, mineração ou diversos tipos de monoculturas, como a da soja, eucalipto, cana de açúcar e outras,

${ }^{3}$ Com a extinção do MDA em 2016 essa contradição se acentua e as forças tornam-se mais desiguais nessa disputa por modelos de desenvolvimento. 
impedindo as populações locais de reproduzirem seus modos de vida nesses locais. Esses projetos impõem riscos às populações, que acabam tendo que assumir o ônus do processo. Contudo, não se transformam em vítimas passivas, e do conflito surge a organização dos grupos atingidos, através de movimentos, associações e redes. É a resposta da vítima (Zhouri \& Oliveira, 2005).

Além disso, fica para o território o desafio futuro de restabelecer novas dinâmicas de desenvolvimento, como descrito por Campolina \& Cavalcante (2017, p. 36) sobre a realidade da região metropolitana de Belo Horizonte, atingida pela mineração, "no curto prazo, o desenvolvimento da região está ligado à dinâmica do setor mineral. A longo prazo, tanto o seu esgotamento quanto o surgimento de materiais substitutos representam desafios para o desenvolvimento da região".

As diversas formas de degradação ambiental afetam de modo desigual diferentes grupos sociais e se concretizam em áreas geográficas onde vivem as populações de menor renda, comunidades tradicionais, negras e indígenas. Esta problemática faz com que surjam movimentos sociais dos sujeitos envolvidos nesses conflitos que procuram equilibrar uma balança de poder, atualmente tão inclinada em favor das empresas multinacionais. As lutas locais se conectam cada vez mais globalmente, fazendo com que conflitos locais engendrem redes internacionais que os respaldem (Alier, 2007).

De acordo com Acserald (2010), esses sujeitos vêm denunciando a exposição desproporcional aos riscos ambientais, sempre orientada para as populações socialmente desprovidas de privilégios, as quais priorizam e dependem do ar puro, da terra disponível e da água limpa, ante os bens comercializados, para se reproduzirem (Alier, 2007).
Esse movimento é pautado na luta pela justiça ambiental que surge como resposta às violações de direitos das populações atingidas pelos diferentes tipos de projetos que concentram os benefícios do desenvolvimento em poucas mãos. A justiça ambiental surge como uma alternativa ao desenvolvimento sustentável, por não poder ser cooptada por análises do tipo custo-benefício ou por avaliações de impacto ambiental, assumindo um caráter revolucionário para "combater as desigualdades na distribuição dos benefícios e prejuízos que são produzidas pelo modelo clássico de economia predominante nas sociedades humanas" (Souza \& Milanez, 2015, p. 6821).

Martins (1993), ao refletir sobre os impactos dos grandes projetos econômicos na vida das populações indígenas e camponesas, afirma que

[...] não se trata de introduzir nada na vida dessas populações, mas de tirar-lhes o que tem de vital para sua sobrevivência, não só econômica: terras e territórios, meios e condições de existência material, social, cultural e política. É como se elas não existissem ou, existindo, não tivessem direito ao reconhecimento de sua humanidade (Martins, 1993, p. 63).

O projeto Minas-Rio aqui tratado pode ser considerado um retrato dessa realidade, tendo em vista que é um projeto de grande porte, com complexa infraestrutura de extração mineral. Possui uma mina de extração de minério de ferro na Serra do Sapo em Conceição do Mato Dentro, uma planta de beneficiamento e barragem de rejeitos em Alvorada de Minas, um mineroduto para transporte do minério até o litoral, que atravessa 33 municípios, sendo 26 de Minas Gerais e 7 do Rio de Janeiro, com $525 \mathrm{~km}$ de extensão - o maior mineroduto do 
mundo - e um porto, chamado Porto do Açu em São João da Barra - RJ. O projeto Minas-Rio tem capacidade de produção de 26,5 milhões de toneladas de minério de ferro por ano, sendo destinados, principalmente, para o mercado externo (Milanez et al., 2013; Zucarelli \& Santos, 2015). Inicialmente o projeto Minas-Rio foi da empresa MMX S.A., mineradora do empresário Eike Batista, porém, em 2008 a empresa Anglo American, grupo britânico, o comprou, gerando aproximadamente 5,5 bilhões de reais de lucro para a MMX (Barcelos, 2013; Tôrres, 2014). A empresa Anglo American está no Brasil desde 1973, atuando em negócios de níquel, nióbio e fosfatos, e a partir de 2008 com minério de ferro. Inevitavelmente tal empreendimento gera efeitos e consequências severas sobre as populações rurais localizadas em seu entorno.

\section{O percurso metodológico}

Do ponto de vista metodológico, a pesquisa foi de natureza qualitativa e buscou explicar a realidade a partir do olhar e da voz dos próprios sujeitos da situação social. A pesquisa de campo foi realizada por uma equipe multidisciplinar composta por assessores técnicos da Cáritas, professores, mestrandos e graduandos da UNIFEI, que adotou como instrumentos de pesquisa métodos qualitativos como entrevistas, conversação e observação. O processo de coleta de dados demandou a visitação da equipe de pesquisa nos três municípios atingidos pelo empreendimento minerário. Foram realizadas 55 entrevistas entre as famílias agricultoras dos municípios, divididas da seguinte forma: $31 \mathrm{em}$ Conceição do Mato Dentro, 11 em Alvorada de Minas, 13 em Dom Joaquim. Também foram en- trevistados os secretários municipais de agricultura, bem como técnicos da Empresa de Assistência Técnica e Extensão Rural do Estado de Minas Gerais (EMATER), representantes dos Sindicatos de Trabalhadores Rurais (STRs) e do Conselho de Desenvolvimento Rural Sustentável (CMDRS) dos três municípios pesquisados.

A escolha das comunidades se deu a partir da divisão dos municípios em "regiões-tipo", a partir de quem os conhecia do ponto de vista das suas condições naturais e sociais - Sindicato dos Trabalhadores Rurais, Conselho Municipal de Desenvolvimento Rural Sustentável (CMDRS) e EMATER-MG, bem como pela equipe da Cáritas, por meio de reunião conjunta com seus representantes e com o auxílio de um mapa para divisão em regiões-tipo. Buscou-se abarcar tanto as comunidades rurais com melhores características produtivas e de integração comercial na região, quanto as comunidades com maiores dificuldades produtivas e com desestruturação decorrente da atividade minerária. A partir deste instrumento chegou-se a divisão dos municípios em quatro categorias (Figura 2):

1. Desestruturação: áreas de maior vulnerabilidade sócio-econômica;

2. Unidades Familiares: áreas com grande número de unidades de produção familiares;

3. Produtividade: áreas de maior produtividade;

4. Integração Produtiva: áreas de grande integração produtiva com a cidade, com comercialização significativa.

Em Alvorada de Minas foram 5 regiões de estudo com amostra de 11 entrevistas, nas comuni- 
dades de 1) Lapinha e Ribeirão Santana; 2) Fazenda da Ponte; 3) Descoberto e Bom Jesus; 4) Serra dos Monteiros; 5) Ribeirão de Trás. Em Conceição do Mato Dentro foram 9 regiões de estudo, abrangendo 17 comunidades, totalizando em uma amostra de 31 entrevistas em: 1) Capitão Felizardo; 2) Costa Sena e Goiabeiras; 3) Tapera e Santo Antônio do Cruzeiro; 4) Ouro Fino e Córregos; 5) Água Quente e Sapo; 6) Parauninha e Itacolomi; 7) Tabuleiro; 8) Três Barras, Buraco e Cubas; 9) Brejaúba e Socorro. Em Dom Joaquim foram 5 regiões de estudo com uma amostra de 13 entrevistas, nas comunidades de: 1) Cachoeira; 2) Machado; 3) São José da Ilha; 4) Sesmaria e Serra; 5) São João.

As entrevistas abrangeram informações sobre a produção das famílias agricultoras da comunidade, as formas de comercialização e de organização e os usos da terra e da água, e - o recorte utilizado neste trabalho - o potencial produtivo das famílias agricultoras e as mudanças ocorridas devido a instalação e operação da mineração.

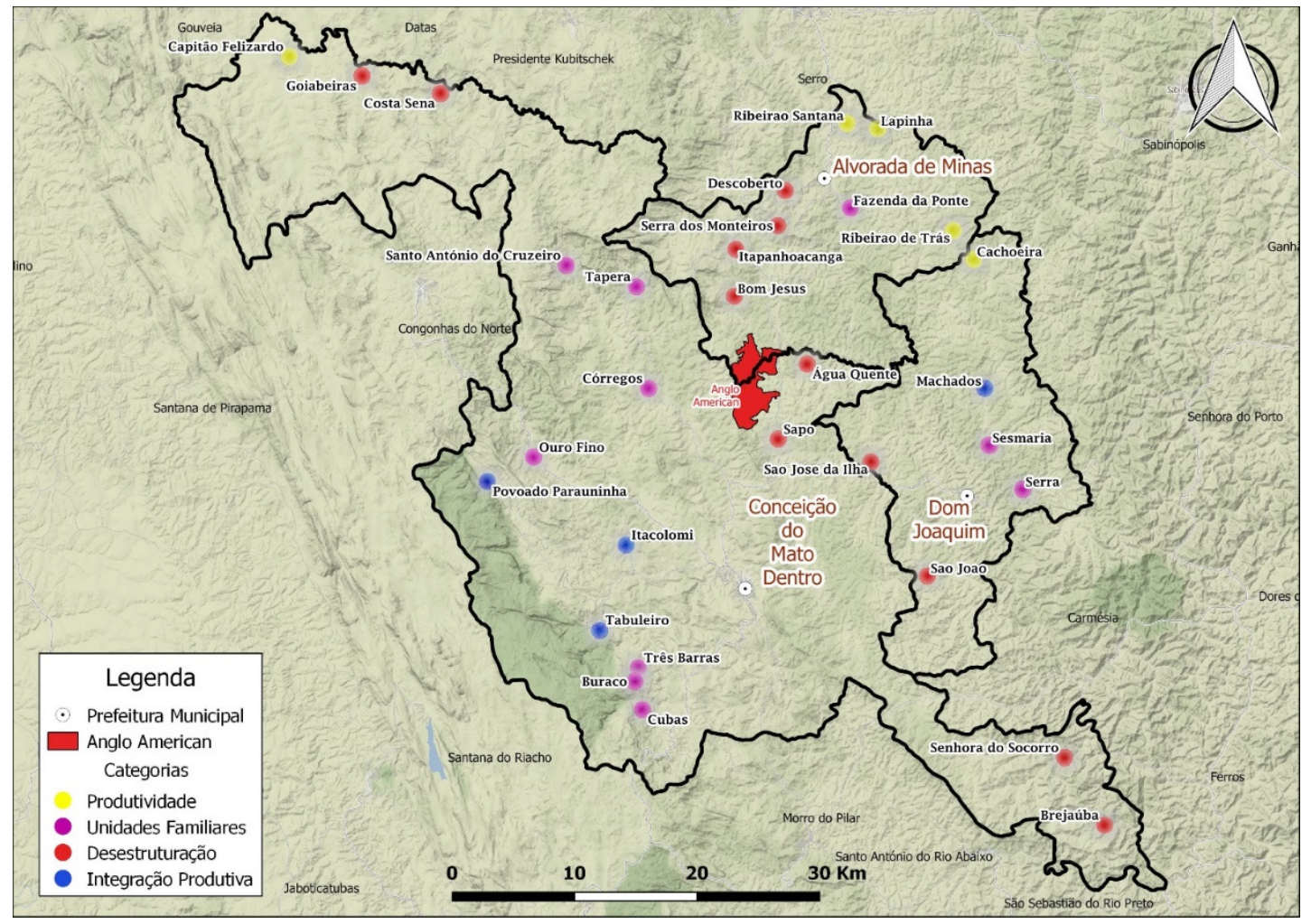

FIGURA 2 - Divisão da amostra em categorias.

FONTE: Núcleo Travessia (2016). 


\section{O potencial produtivo das comunidades rurais atingidas}

A agricultura familiar é heterogênea e pluriativa. Segundo Breitenbach (2018, p. 55), as principais características que diferenciam a agricultura familiar das demais formas de produção agropecuária (empresarial e patronal) são: "[...] o trabalho e gestão intimamente relacionados; ênfase na diversificação; ênfase na durabilidade dos recursos naturais e na qualidade de vida; trabalho assalariado complementar; e ênfase no uso de insumos internos".

Na região que abrange os municípios de Conceição do Mato Dentro, Alvorada de Minas e Dom Joaquim, o contingente de agricultores familiares representa $79,5 \%$ da população total. O município que apresenta o maior índice de estabelecimentos da agricultura familiar é Conceição do Mato Dentro, com $81,1 \%$ dos estabelecimentos existentes no meio rural. É na agricultura familiar que se encontra a maior parte da população rural do país, da mesma forma que acontece na região estudada como um todo e em seus municípios separadamente, refletindo a realidade brasileira. Assim, também nos municípios Conceição do Mato Dentro, Alvorada de Minas e Dom Joaquim a agricultura familiar contribui efetivamente para a geração de ocupação e renda locais (IBGE, 2006).

As principais lavouras cultivadas na região estão distribuídas em roças de cana, milho, feijão, mandioca e café, que têm como destino não só o autoconsumo familiar, mas também o comércio e as trocas comunitárias (Figura 3). A cana e o milho têm como destino certo o trato dos animais. O feijão,

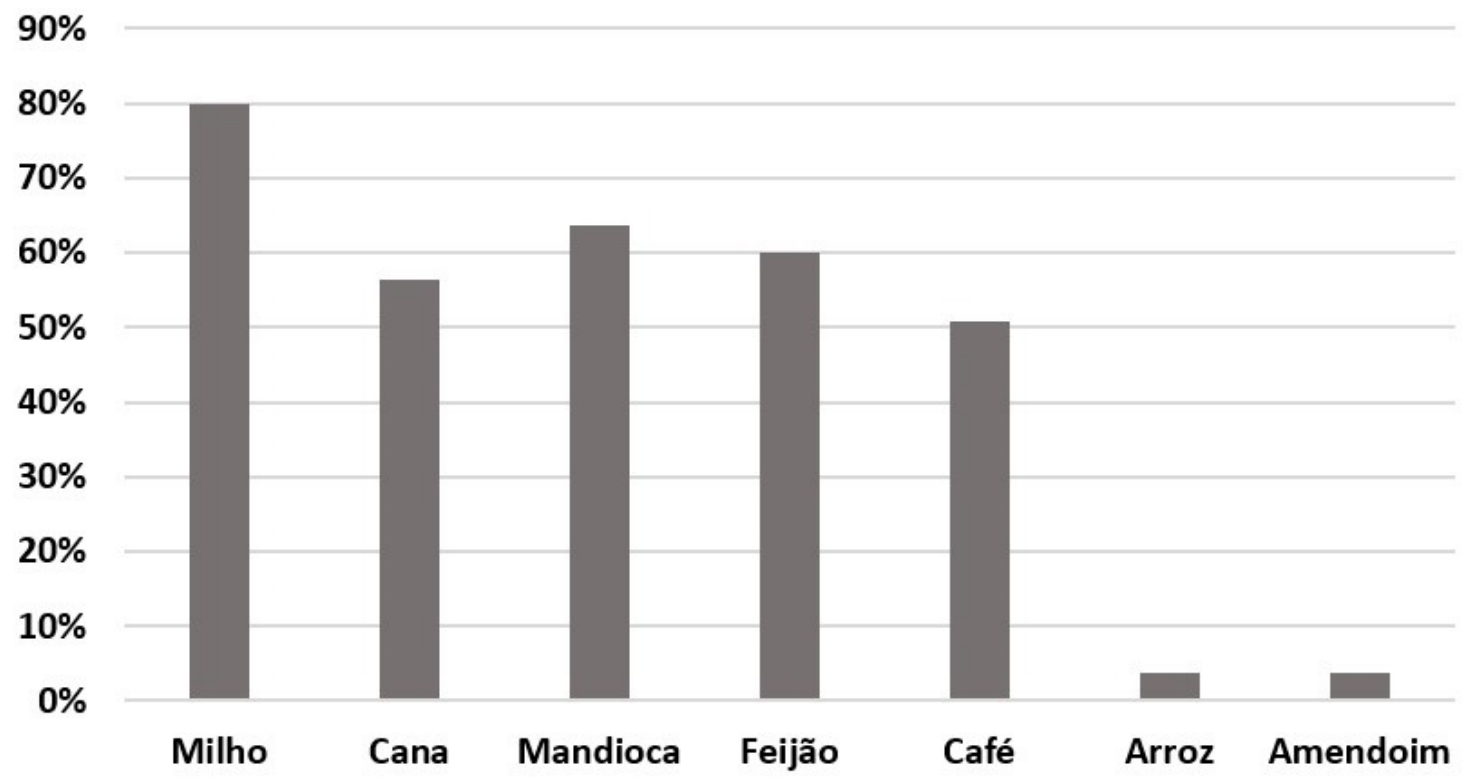

FIGURA 3 - Percentual de lavouras cultivadas pela amostra pesquisada. FONTE: Pesquisa de campo, 2016. 
também produzido para autoconsumo, eventualmente pode exceder e direcionar-se ao comércio. A cana de açúcar, que é uma roça perene, destina-se não apenas para o trato animal (forragem), mas também para a produção de cachaça e rapadura. A produção tem como objetivo primordial garantir a satisfação de suas necessidades, que é em si a motivação do trabalho, e não a realização do lucro, ou em outras palavras: parte-se da necessidade de consumo, da manutenção da família, de sua reprodução social, para entender seu trabalho, o que se traduz pelo conceito de "modo de produção doméstico" de Chayanov (1974), que expressou a lógica camponesa em contraste à lógica capitalista.

A mandioca, também planta semi-perene, é produzida para o consumo de mesa e para a produção de farinha, que por sua vez excede o consumo e pode ser comercializada ou ainda servir como produto de troca nas mercearias. A mandioca de mesa é menos produzida do que a mandioca brava, utilizada na produção de farinha. Ainda está presente a maneira tradicional nas formas de produção: plantio de variedades de sementes (especialmente feijão), consórcio no plantio e utilização do esterco (abundante por causa do gado) que é utilizado como recurso, principalmente no plantio das hortaliças, legumes e frutas. Existem ainda na região famílias que produzem sem o uso de maquinário, devido à boa qualidade das terras (Núcleo Travessia, 2016).

Através da pesquisa de campo percebeu-se a forte vocação produtiva da região na produção de leite/queijo, presente em muitas comunidades. $\mathrm{O}$ destaque na atividade leiteira para a produção do queijo pode ser explicado, em partes, pela relação com o município do Serro. A região se destaca pela pecuária de leite, como uma atividade econômica identitária. Esta atividade ultrapassa o sentido me- ramente econômico/mercantil, indo em direção a um sentido de reprodução social. O leite serve para o consumo e dele produz-se o queijo, o requeijão, a mussarela, além dos doces e quitandas, tudo isso para o consumo, bem como para a comercialização. Isso mostra, conforme os estudos de Wolf (1970) sobre o relacionamento do campesinato com a sociedade envolvente, que as famílias rurais produzem excedentes que são destinados à sociedade mais ampla em que estão inseridos e se constituem como uma categoria que se relaciona com outros grupos sociais, embora sempre como grupo subordinado.

A produção de queijo apresentou grande potencial, pois é produto atrativo em todo o estado. Contudo, na região essa produção enfrenta a problemática do registro/cadastro no IMA (Instituto Mineiro de Agropecuária), instituição responsável pela inspeção sanitária e industrial dos produtos de origem animal. Nem todos os produtores de leite da região conseguem se adequar às normas estabelecidas pela instituição, principalmente para a produção do queijo. Isto reforça o debate sobre as exigências da legislação sanitária e a tradição familiar de agricultores e agricultoras na produção de queijo na região. Há um importante argumento de que as famílias agricultoras ficam sujeitas às imposições e normas que são direcionadas às demais indústrias processadoras de alimentos, e generalizam um saber-fazer que é particularizado, regionalizado, culturalizado, negando assim as práticas e os saberes tradicionais das famílias. Ao buscarem adequação dos seus produtos do ponto de vista da legislação, são levados a pensar e agir como numa "linha de produção", abandonando parte de seu modo de fazer tradicional, que guarda relação com os aspectos culturais da localidade, com o conhecimento do ambiente, com o domínio da técnica 
e lógica próprias da agricultura familiar. Além dos padrões demandarem de alto custo financeiro, o qual as famílias não possuem (Núcleo Travessia, 2016).

Por esta razão a venda dos queijos acontece comumente de forma clandestina, indo principalmente para os municípios de Curvelo, Diamantina, Belo Horizonte, João Monlevade e Ipatinga. O IMA possui o Programa Queijo Minas Artesanal - feito a partir de leite cru, não pasteurizado — que promove a identidade dos queijos artesanais produzidos nesta e em outras regiões do estado, mas ainda parece estar muito distante da realidade dos produtores destes municípios, pois possui exigências a serem atendidas referentes à produção, equipamentos, higiene, controle de saúde dos trabalhadores e dos animais, dentre outros, tão distantes das práticas produtivas das famílias agricultoras.

$\mathrm{O}$ que se percebeu com isso foi que apesar do destaque para a pecuária leiteira, não se pode dizer que os agricultores abriram mão da diversificação das atividades como estratégia de sobrevivência, pois a "vocação" para a diversidade de variedade cultivadas é intrínseca à categoria dos agricultores familiares. Ao refletir sobre a relação estabelecida entre camponês e terra, Woortmann (2004) descreve uma reciprocidade positiva estabelecida entre ambos, onde ele (o camponês) deve "tratar bem a terra", preparando-a, alimentando-a, e ela, em agradecimento, retribui esse trabalho com a produção abundante, com fartura.

Os quintais das casas - lugar do pomar, horta, chiqueiro, galinheiro - representam o resultado do trabalho na formação do terreno familiar, e são importantes fontes de segurança alimentar das famílias. A horta e o pomar possuem produtos variados, mas não com a mesma abundância em todas as regiões. Na horta se cultiva couve, agrião, salsa, mostarda, repolho, alface, cebolinha, brócolis, rúcula, quiabo, abóbora, inhame, beterraba, cenoura, batata doce, espinafre, escarola, taioba, chuchu e alho. Produz-se toda sorte de frutas perenes: mexerica, laranja, goiaba, manga, banana (prata e caturra), limão (taiti e galego) e acerola. Há também as frutas nativas do cerrado, como a cagaita, o pequi, a gabiroba e a panã/araticum, que são frutos de época e que normalmente não são comercializados. Os dados de campo mostraram que nestas comunidades se mantém um contato imediato dos habitantes com o meio natural e, na medida em que incorpora isso como um valor a ser preservado, as práticas de exploração sustentáveis da biodiversidade ganham força, o que pode ser traduzido pelo conceito de ruralidade.

No estudo realizado por Breitenbach (2018) no estado do Rio Grande do Sul, a autora destacou a importância das atividades de subsistência para a dinâmica econômica das famílias agricultoras, ou seja, embora a produção seja destinada ao consumo familiar ela representa economia e autonomia, além de estar relacionada à preservação de alimentos nativos, como observado nesta pesquisa.

A criação de pequenos animais (Figura 4), como galinhas, porcos e, em poucos casos, peixes, são voltadas para o autoconsumo familiar, mas também são comercializadas. Em alguns casos também há criação de abelhas para produção de mel, tanto para o autoconsumo familiar quanto para o comércio local. A criação de porcos tem como finalidade complementar a alimentação familiar, e muito pouco para o comércio. Galinhas e ovos são comercializados, sendo que os ovos têm, em determinadas épocas do ano como na quaresma, uma grande saída. Assim, ambos — galinhas e ovos - representam uma fonte complementar de 


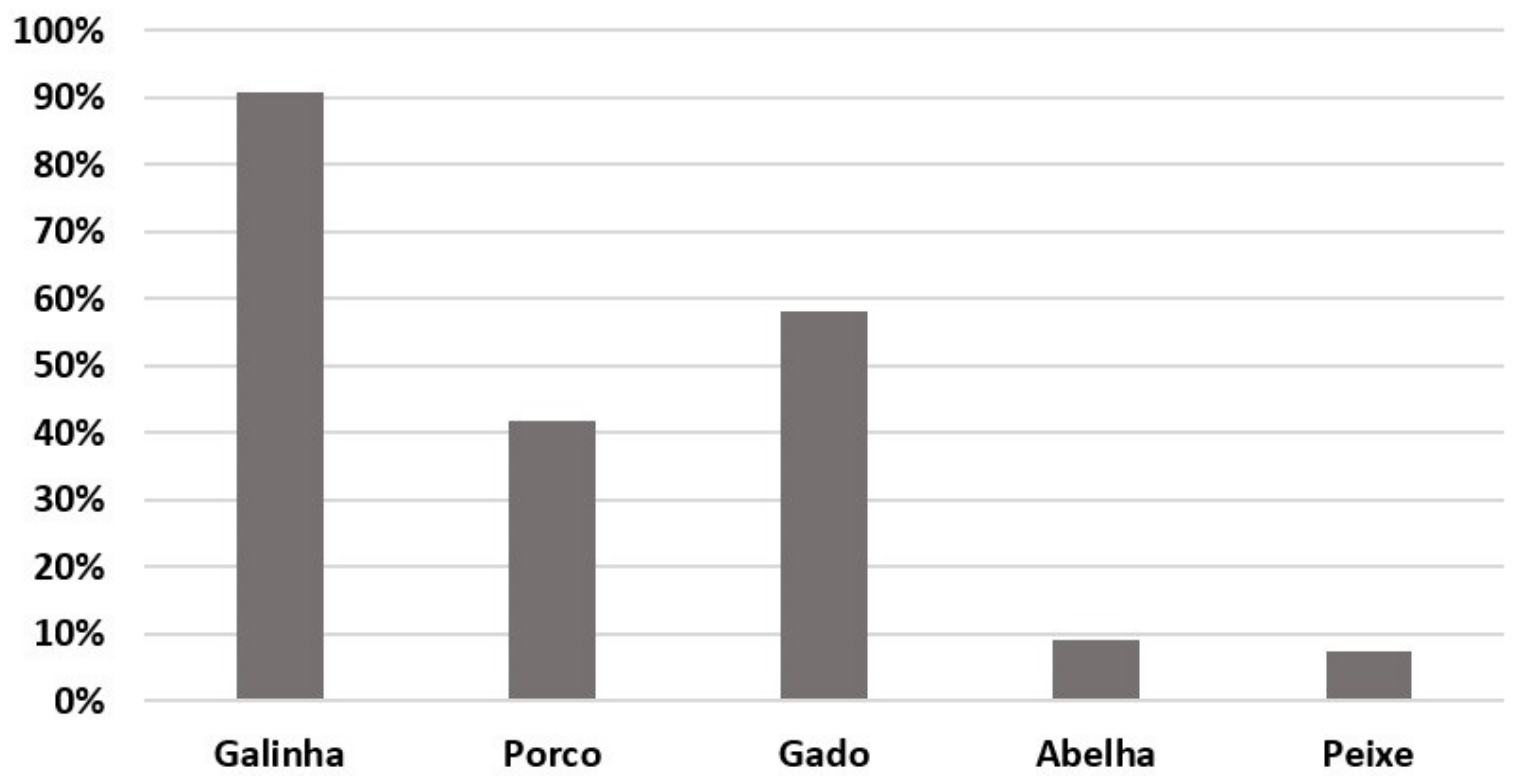

FIGURA 4 - Percentual de criações animais da amostra pesquisada. FONTE: Pesquisa de campo, 2016.

alimentação e renda das famílias agricultoras. Outra fonte de renda é a venda de bezerros, haja vista que estão habituados a mexer com o gado mais mestiço, comprado na região mesmo, que cria o bezerro e dá o leite (Núcleo Travessia, 2016). Esta é uma característica importante do campesinato: quando há excedentes, faz-se a troca direta entre os membros da própria comunidade, isso demonstra a forte sociabilidade existente no campesinato.

A indústria doméstica rural na região se caracteriza por criar um produto artesanal, com inserção em mercados locais, com processos produtivos específicos e definidos pelos recursos do local. Além do queijo, requeijão, mussarela, quitandas e doces, são produzidos também farinha de mandio- ca, fubá de milho, polvilho, geleias de frutas, mel, própolis, cachaça, melado e rapadura (Figura 5). A infraestrutura costuma ser comum, de forma que os produtos são produzidos nas próprias cozinhas, com os pequenos equipamentos que possuem, mas em alguns casos há o uso de casas próprias para produção, como casas de farinha, casas de queijo, engenho e alambique (Núcleo Travessia, 2016).

As casas de farinha são compostas por descascador de mandioca, ralador, forno de pedra e torrador; as casas de queijo por tambor para armazenamento do leite, saco para secagem do soro, pá para a quebra do coalho, panela para cozimento, forma, mesa/pia para descanso do queijo, freezer para armazenamento/conservação e alguns casos 


\section{$35 \%$}

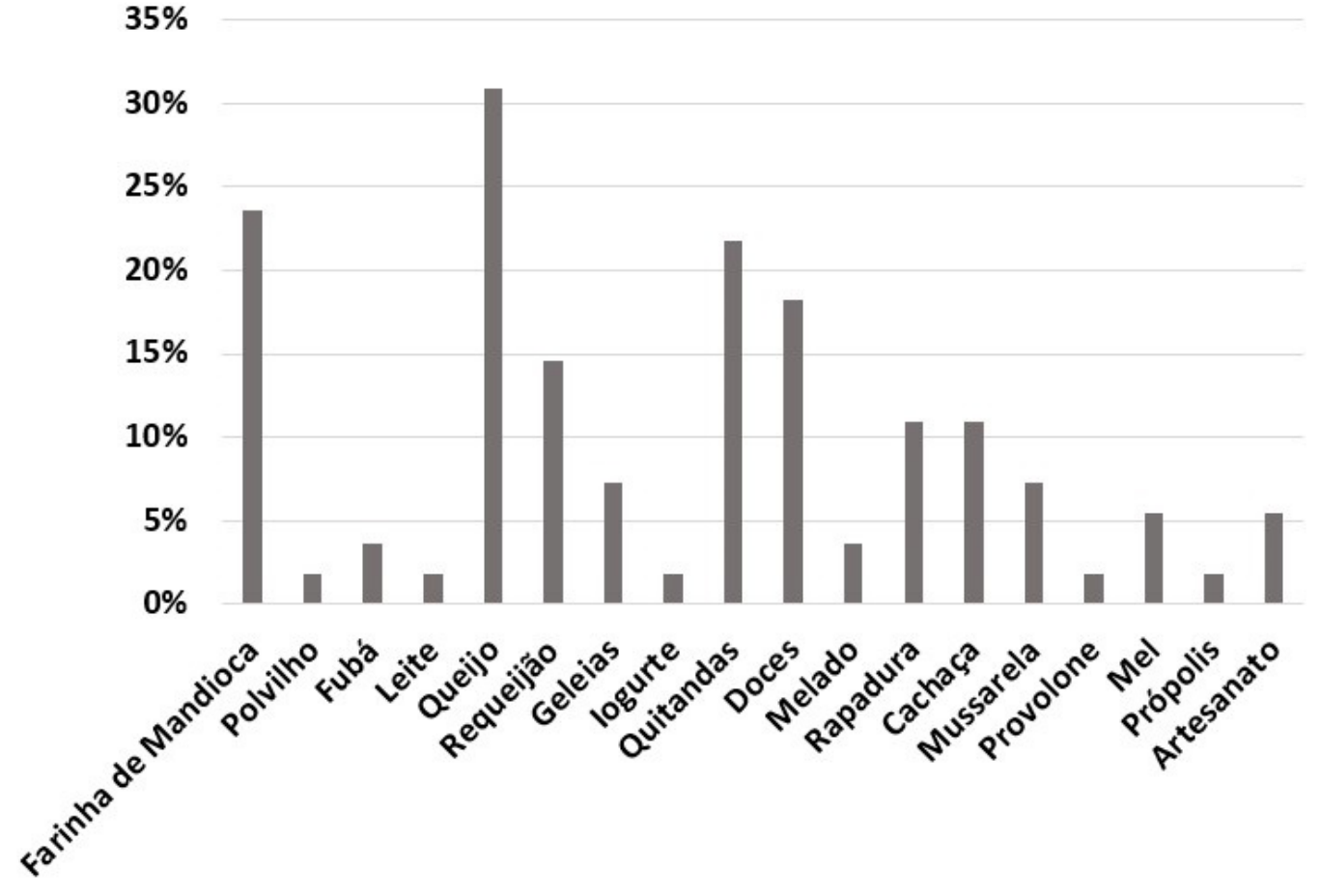

FIGURA 5 - Percentual de produtos beneficiados pela amostra pesquisada.

FONTE: Pesquisa de campo, 2016.

balança para pesagem. As quitandas (biscoito de polvilho, biscoito de amendoim, rosquinhas e pão de goiabada) são feitas com estrutura mínima: forno a lenha, geladeira para conservação da manteiga, do leite e ovos, moinho d'água para produção de fubá panela, tacho e vasilhas comuns; os doces (de laranja, limão e goiaba) e as geleias de frutas dependem de uma estrutura que contenha fogão a lenha, forno e formas, que pode estar presente dentro das próprias cozinhas das casas. Para a produção de rapadura precisa-se do engenho, tacho e formas (Núcleo Travessia, 2016).
O fato de serem simples suas estruturas não significa que sejam ineficientes, ao contrário, há todo o cuidado por parte das famílias em se manter a qualidade de seus produtos porque seus consumidores são visíveis, conhecidos, sejam na feira livre, nas mercearias, ou de porta em porta, como também exigem o produto num padrão costumeiro e numa especificação bastante definida. Não se trata, contudo, de um padrão fordista, mas de uma cultura material, dentro de critérios próprios de apreciação, estabelecida pelo paladar, com suas raízes na formação da cultura da região. 
Com relação a mão-de-obra da região os dados da pesquisa mostraram que prevalece o trabalho familiar, característica da agricultura familiar em qualquer região do país - utilização predominantemente de mão-de-obra da própria família nas atividades econômicas de suas unidades de produção. A contratação de dia de serviço pago acontece em poucos casos, pois não é viável financeiramente para as famílias, sendo o mutirão e a troca de dias de serviços e estratégias utilizadas para suprir a necessidade de mão de obra. Contudo, o trabalho nas unidades familiares da região não tem sido suficiente para garantir a renda necessária, impulsionando a busca por outras atividades que completem a renda familiar, como a prestação de serviços rurais em fazendas, serviços de faxina na sede municipal urbana, trabalhos na própria mineração. Essa saída não pode ser vista como uma transformação desses agricultores e agricultoras que teria como resultado a proletarização (futuro operário), pois se as atividades não agrícolas em determinado momento oferecem ganhos superiores à produção agrícola, a mão de obra familiar tende a migrar para essa direção, para alcançar o equilíbrio interno de forma mais rápida (Chayanov, 1974). Assim, os agricultores e agricultoras montam estratégias reais de sobrevivência, através de um conjunto de ações coerentes, que lhes garantem sua reprodução social — persistem, labutam com fôlego, criam, recriam, vão e vêm, sem trégua. E é essa mobilidade, essa maleabilidade e essa maestria que os permite, ainda hoje, permanecerem como tais.

Percebe-se assim, de maneira geral, uma abundância de alimentos, que são produzidos para o consumo, venda e trocas, e não exclusivamente para o comércio. Talvez por isso pesquisadores, planejadores, técnicos, extensionistas, agentes de desenvolvimento rural e tomadores de decisões não compreendam seus sistemas próprios de produção e organização social e consequentemente todo o seu potencial. Por outro lado, toda esta diversidade e independência, estão ameaçadas pela atividade minerária. Os agricultores começam a sofrer dificuldades em manter sua produção, principalmente nas regiões mais próximas da mina de extração, devido a diversos fatores provocados pela mineração.

\section{Os impactos provocados pelo empreendimento minerário}

Desde o início do empreendimento, por volta de 2008, os moradores das comunidades rurais começaram a lidar com uma série de irregularidades ocorridas por parte da empresa, como as aquisições de terra forçadas e o não atendimento das condicionantes exigidas no processo de licenciamento ambiental (Zhouri, 2014). Apesar de não serem reconhecidas como comunidades diretamente atingidas pelo empreendimento, fato que viabiliza o abandono por parte da empresa, os moradores passaram por uma mudança significativa em seu cotidiano.

$\mathrm{O}$ acesso aos recursos naturais, que antes eram abundantes, de uso comum, foram privatizados não permitindo à população local, historicamente e tradicionalmente vivente lá, compartilhar o espaço produtivo do rural, proibindo o acesso a estes recursos (Belleze, 2017). Isso trouxe graves dificuldades para a produção de seus alimentos, a manutenção de suas práticas culturais e, consequentemente, a permanência das famílias em suas terras (Brito, 2018).

Os dados de campo mostraram que a mineração alcançou as regiões de formas distintas, 
sendo também percebida de formas diferentes pelas famílias agricultoras. A visão que possuem acerca do empreendimento tem a ver com a distância que estão situados da cava da mina. Quanto mais perto, mais fortes, diretos e visíveis os impactos sobre as famílias agricultoras; e consequentemente mais comprometidas ficam sua produção material e sua reprodução social. Mas o alcance dos impactos é de grandes dimensões, desde seus deslocamentos compulsórios devido à implantação da mina, passando pela interrupção do acesso aos recursos naturais como florestas e pesca, pela exposição a situações de riscos (prostituição, drogas, violência criadas com a chegada de novos trabalhadores), até a perda da qualidade de vida (poluição sonora, do ar, mudanças na paisagem). De acordo com Campolina \& Cavalcante (2017), os impactos ambientais provocados por este tipo de empreendimento são muitas vezes distintos, no entanto na extração de ferro existem dois grandes passivos ambientais em comum - as barragens de rejeitos e as cavas, que colocam diretamente em risco os recursos hídricos das regiões.

Os prejuízos na produção foram percebidos nas comunidades rurais mais próximas das terras adquiridas pela mineradora para fazer sua reserva legal, e nas proximidades da mina de extração, sendo compostas pelas famílias agricultoras que são atingidas de maneira mais intensa. Os efeitos são tantos e tão complexos nessas comunidades, que se refletem no comprometimento de sua produção material, aumentando a vulnerabilidade, subordinação e dependência de inúmeras famílias agricultoras. As famílias não conseguiram mais produzir seus próprios alimentos, tendo de adquirir em supermercados e mercearias tudo que antes produziam em suas terras. Na comunidade de Água Quente/
Conceição do Mato Dentro, os agricultores relataram que os frutos não desenvolveram mais, ficaram ressecados e pequenos e não serviram de alimento. Em Descoberto/Alvorada de Minas, as famílias não conseguiram produzir as próprias sementes de tão incerta que se tornou a quantidade produzida, além de não poderem continuar a plantar suas lavouras devido a diminuição de terras disponíveis, gerando uma brusca redução de suas rendas (Belleze, 2017).

O esvaziamento do campo foi percebido através da pesquisa em diferentes comunidades e passou a ser um dos agravantes do comprometimento da produção da agricultura familiar da região e do fim de celebrações tradicionais. Algumas famílias agricultoras tiveram que captar água de pior qualidade, pois as nascentes que utilizavam estão em terras da mineradora, assim como, muitos fazendeiros que mantinham porções de terras para que os posseiros desenvolvessem seus cultivos na meia, venderam suas propriedades, de modo que os agricultores não puderam mais utilizar as terras para produção. A mineradora também impediu o uso de lenha e madeira pelas famílias agricultoras, que eram usadas na cozinha e na construção de cercas e casas; passou a impedir também a coleta de frutos nas matas da região. A privatização dos recursos gerou muitas dificuldades de produção, comprometendo-a completamente.

Além disso, a morte de animais passou a ocorrer nas comunidades próximas de rios e córregos contaminados pela atividade minerária, principalmente do rio Passa Sete e córrego Pereira. As criações animais, como o gado e cavalos, bebiam água desses córregos e morriam devido à intoxicação. Além disso, as águas da barragem de rejeitos não se encontravam cercadas ou protegidas, o que permitiu que alguns animais conseguissem alcançar 
o barramento. O material encontrado nas bordas dessas águas possui uma lama com textura elástica e pegajosa, de modo que os animais ficavam presos no local e morriam. A perda dos animais teve um efeito econômico para as famílias agricultoras, uma vez que representavam uma importante reserva de valor, podendo ser utilizada em casos que julgassem necessário. Em alguns casos os animais foram adquiridos, quando do nascimento de algum filho, como um presente de padrinhos e parentes, chamado de miunça, e que se tornou a poupança da criança até chegar na fase adulta (Woortmann, 1990).

A problemática da água tornou-se bastante séria em toda a região. Os agricultores demonstraram grande sensibilidade com relação a esse problema, sendo que a maioria das famílias passou a enfrentar a escassez, o que afetou diretamente a produção de alimentos das comunidades. Rios foram contaminados e nascentes, córregos e brejos secaram, e a água de uma maneira geral diminuiu, principalmente no período de estiagem. A pesquisa apontou para o fato de que os agricultores compreenderam que há uma problemática em torno da água - falta de chuva, desmatamento, queimadas, falta de preservação contudo, creditaram à empresa Anglo American grandes responsabilidades por esta escassez. Esta escassez hídrica afetou diretamente a família, a lavoura, as criações e as indústrias domésticas rurais (Belleze, 2017).

Os intensos impactos da atividade minerária sobre os recursos hídricos foram conhecidos e constatados por diversos estudos. Dentre estes problemas estão: i) a poluição e contaminação de águas superficiais e subterrâneas devido aos rejeitos líquidos contaminantes gerados pelas técnicas utilizadas no beneficiamento do minério, ii) o rebaixamento do lençol freático devido a drenagem de elevados volumes de água durante a escavação e iii) o intenso consumo em todas as etapas da atividade minerária, iv) a supressão da vegetação nas áreas de exploração que aumentaram o escoamento superficial e impossibilitaram a recarga de águas subterrâneas pela infiltração de água das chuvas, levando ao secamento das nascentes e a alteração do regime hidrológico local e v) o assoreamento dos corpos d'água do entorno devido aos processos erosivos e deslizamentos de terra (Bacci et al., 2006; Mechi \& Sanches, 2010; Faleiro \& Lopes, 2010; Rosa, 2014).

No presente estudo os dados de campo mostraram que várias comunidades foram impactadas diretamente pela mineradora, desde a extinção de nascentes e áreas de preservação, até a contaminação de cursos d'água, causando total dependência e subordinação à mineradora. A maioria das famílias passou a fazer captação de água através de nascentes, mas também passaram a usar cisternas, poço da comunidade, córregos e, no caso das comunidades fragilizadas pela mineradora, captação de uma caixa d'água abastecida por um caminhão pipa contratado da Anglo, como medida de compensação pelo estrago hídrico por ela causado.

Todos esses impactos já foram percebidos pelos agricultores em toda a região, nos primeiros anos de atividade minerária. A maioria das famílias reconheceram o atingimento sobre o abastecimento humano e animal. O desenvolvimento de atividades que dependiam dos recursos hídricos como a pesca, a produção de alimentos das comunidades, a lavagem de roupa, além dos momentos de recreação e lazer, foram impactadas pelo empreendimento minerário.

O resultado dessa ação expropriadora foi a vulnerabilidade destas famílias, devido ao comprometimento da produção e criação animal, bem como 
da reprodução social das famílias agricultoras. A produção da região, comprometida pela mineradora, deixou de ser suficiente para garantir o consumo alimentar, tornando as comunidades mais vulneráveis e carentes. Para completar o quadro de abuso dos direitos ambientais dessas famílias, a empresa Anglo American realizou visitas na região com o intuito de comprar mais terras, pressionando as poucas famílias resistentes, e também para fiscalizar a extração de lenha por elas. Assim, as características desses projetos revelam a lógica perversa que tem sido imposta sistematicamente aos "territórios" considerados "deprimidos".

Se o território rural da região pesquisada era o enraizamento, a referência, o lugar de vida e de trabalho das populações rurais, o que o projeto minerário fez foi provocar o fluxo, a descontinuidade, o rompimento de fronteiras e de relações.

\section{Conclusões}

A região estudada é caracterizada pela presença marcante da agricultura familiar, com potencial para alavancar o desenvolvimento em bases sustentáveis, através de produção rica e processos de beneficiamento tradicionais que carregam valor material e guardam valor imaterial. Agricultores de Conceição do Mato Dentro, Alvorada de Minas e Dom Joaquim - MG possuíam uma produção material diversificada e consolidada por meio de práticas tradicionais de uso da terra e água, garantindo suas lavouras, hortas, pomares, criações animais e produtos de agroindústrias domésticas rurais, tanto para autoconsumo familiar quanto para comercialização. Contudo, esses agricultores, com a chegada do projeto Minas-Rio, passaram a enfrentar dificuldades em manter sua produção, principalmente nas regiões mais próximas da mina de extração, devido a diversos fatores provocados pela mineração.

A mineração, caracterizada por um projeto de grande porte e de grandes impactos socioambientais, chegou na região de forma a desestruturar a produção e a reprodução social dos agricultores familiares, provocando a desterritorialização e alterando drasticamente os rumos do desenvolvimento rural em bases sustentáveis e territoriais.

Cabe reconhecer que projetos industriais desse porte, como a mineração, hidrelétricas e monoculturas, são criadores de conflitos socioambientais, ou ainda, injustiças ambientais, sendo que o conflito é gerado quando a utilização dos recursos é apropriada por um determinado grupo em detrimento dos usos que outros grupos possam fazer de seu território e, com isso, assegurar a reprodução do seu modo de vida, como tem acontecido na região em estudo.

Esse cenário evidenciou a forma como a mineradora alcançou o rural da região e promoveu um descompasso de lógicas, expresso pelo intenso confronto entre o desenvolvimento da atividade minerária e o desenvolvimento do modo camponês conduzido por gerações, devido a uma lógica própria de vida e de relação com o mundo, que passou a ser fortemente ameaçada pela mineração. Ao invés de promover o desenvolvimento das comunidades rurais, a atividade minerária provocou a desestruturação produtiva, social, cultural e ambiental da localidade onde se instalou, promovendo sérias consequências para as famílias agricultoras, expressas pelas dificuldades de permanência em suas terras. O projeto de "desenvolvimento" impresso na região pela mineração, caminhou no sentido da 
expropriação do campesinato existente, devido a concentração de terras e ao agravamento do problema fundiário que a mineradora provocou, além de todas as limitações impostas às famílias agricultoras para manter suas estratégias de reprodução social, de acordo com as mudanças percebidas por elas próprias. Porém, apesar das dificuldades e entraves, as famílias desenvolveram estratégias e diversas maneiras de resistir e permanecer em suas terras, mas como o empreendimento ainda está em fase inicial, torna-se difícil prever o grau de resiliência dessas famílias.

\section{Agradecimentos}

Agradecemos à Cáritas Brasileira - Regional Minas Gerais, pelo apoio financeiro a esta pesquisa, bem como à equipe de Conceição do Mato Dentro, cujo suporte foi fundamental para a realização da mesma.

\section{Referências}

Abramovay, R. Capital social dos territórios: repensando o desenvolvimento rural. Economia Aplicada, 4(2), 379397, 2000.

Abramovay, R. O futuro das regiões rurais. Porto Alegre: UFRGS, 2003.

Acselrad, H. Ambientalização das lutas sociais - o caso do movimento por justiça ambiental. Estudos avançados, 24(68), 103-119, 2010. doi: 10.1590/S010340142010000100010

Alier, J. M. O ecologismo dos pobres. São Paulo: Contexto, 2007.

Arrighi, G. A Ilusão do desenvolvimento. Petrópolis: Editora Vozes, 1997.
Bacci, D. de L. C.; Landim, P. M. B.; Eston, S. M. Aspectos e impactos ambientais de pedreira em área urbana. REMRevista Escola de Minas, 59(1), 47-54, 2006. doi: 10.1590/ S0370-44672006000100007

Barcelos, E. O projeto minas rio e seus impactos socioambientais: olhares desde a perspectiva dos atingidos. Relatório Preliminar. Minas Gerais; Rio de Janeiro: Produzido no âmbito do Encontro de Intercâmbio das Comunidades em Resistência ao Projeto Minas-Rio, 2013.

Belleze, G. Comunidades rurais tradicionais atingidas pelo projeto de mineração Minas-Rio: Afinal, desenvolvimento para quem? Itajubá, Dissertação (Mestrado em Desenvolvimento, Tecnologias e Sociedade) - UNIFEI, 2017.

Breitenbach, R. Participação econômica das atividades de subsistência na agricultura familiar. Redes, 23(1), 53-68, 2018. doi: 10.17058/redes.v23i1.6780

Brito, T. P. Desenvolvimento Rural e Políticas Públicas: desafios e possibilidades do PNAE em região atingida pela mineração. Itajubá, Dissertação (Mestrado em Desenvolvimento, Tecnologias e Sociedade) - UNIFEI, 2018.

Bruno, R. Desigualdade, agronegócio, agricultura familiar no Brasil. Estudos Sociedade e Agricultura, 24(1), 142-160, 2016. Disponível em: https://revistaesa.com/ojs/index.php/ esa/article/view/712

Campolina, B.; Cavalcante, A. Economia minerária e seu impacto urbano: desafios e contradições na Região Metropolitana de Belo Horizonte. Redes, 22(1), 12-39, 2017. doi: 10.17058/redes.v22i1.8546

Carneiro, M. J. Política pública e agricultura familiar: uma leitura do Pronaf. Estudos Sociedade e Agricultura, 8(1), 70-82, 1997. Disponível em: https://revistaesa.com/ojs/ index.php/esa/article/view/106

Chayanov, A. V. La organización de La unidad econômica campesina. Bueno Aires: Nueva Visión, 1974.

Delgado, G. Capital Financeiro e Agricultura no Brasil, 1965-1985. São Paulo: INCONE/UNICAMP, 1985.

Delgado, G.; Bergamasco, S. Agricultura familiar brasileira: desafios e perspectivas de futuro. Brasília: Secretaria Especial de Agricultura e do Desenvolvimento Agrário, 2017. Disponível em: <https://www.cfn.org.br/wp-content/ 
uploads/2017/10/Agricultura_Familiar.pdf $>$. Acesso em: dez. 2018.

Faleiro, F. F.; Lopes, L. M. Aspectos da mineração e impactos da exploração de quartzito em Pirenópolis-GO. Ateliê Geográfico, 4(11), 148-162, 2010. Disponível em: http:// rigeo.cprm.gov.br/jspui/bitstream/doc/604/1/art_quartzito_Faleiro.pdf

Furtado, C. O Mito do Desenvolvimento Econômico. Rio de Janeiro: Editora Paz e Terra, 1974.

Furtado, C. Introdução ao Desenvolvimento. Rio de Janeiro: Editora Paz e Terra, 2000.

IBGE - Instituto Brasileiro de Geografia e Estatística. Censo Agropecuário 2006: Brasil, Grandes Regiões e Unidades da Federação. Rio de Janeiro, 2009. Disponível em: $<$ https://biblioteca.ibge.gov.br/visualizacao/periodicos/51/agro_2006. pdf $>$. Acesso em: nov. 2017.

Lamarche, H. A agricultura familiar: comparação internacional. Campinas: UNICAMP, 1993.

Martins, J. de S. Chegada do estranho. São Paulo: Hucitec, 1993.

Mechi, A.; Sanches, D. L. Impactos ambientais da mineração no Estado de São Paulo. Estudos Avançados, 24(68), 209-220, 2010. doi: 10.1590/S0103-40142010000100016

Milanez, B.; Scotto, G.; Sant'ana Júnior, H. A.; Bossi, D.; Kato, K. Injustiça Ambiental, Mineração e Siderurgia. In: Porto, M. F.; Pacheco, T.; Leroy, J. P. (Org.). Injustiça Ambiental e Saúde no Brasil, o mapa de conflitos. Rio de Janeiro: Editora FIOCRUZ, 2013. p. 175-205.

Núcleo Travessia - Núcleo de Pesquisa, Extensão e Apoio a Agricultura Familiar e Desenvolvimento Rural. Levantamento das potencialidades da agricultura familiar e agroecológica das comunidades rurais atingidas pela mineração nos municípios de Conceição do Mato Dentro, Alvorada de Minas e Dom Joaquim. Relatório de Pesquisa. Itajubá, 2016.

Ortega, A. C. Territórios deprimidos: desafios para as políticas de desenvolvimento rural. Uberlândia: EDUFU, 2008.

Pereira, V. G. Como a vida se refaz: os caminhos da reterritorialização de atingidos pela Barragem de Irapé do Alto Jequitinhonha. Lavras, Tese (Doutorado em Administração)
- Lavras: UFLA, 2013.

Raynaut, C. Interdisciplinaridade; mundo contemporâneo, complexidade e desafios à produção de conhecimentos. In: Jr, A. P.; Neto, A. J. S. Interdisciplinaridade em ciência, tecnologia e inovação. Barueri, SP: Manole, 2011. p. 69-105.

Rosa, J. C. S. Avaliação de impactos ambientais de um projeto de mineração: um teste metodológico baseado em serviços ecossistêmicos. São Paulo, Dissertação (Mestrado em Engenharia Mineral) - USP, 2014.

Sabourin, E. Camponeses do Brasil: entre a troca mercantil e a reciprocidade. Rio de Janeiro: Garamond, 2009.

Schneider, S.; Cassol, A. Diversidade e heterogeneidade da agricultura familiar no Brasil e algumas implicações para políticas públicas. In: Delgado, G. C.; Bergamasco, S. M. P. P. (Orgs.). Agricultura familiar brasileira: desafios e perspectivas de futuro. Brasília: Secretaria Especial de Agricultura e do Desenvolvimento Agrário, 2017. p. 82-107.

Souza, L. R. C. de; Milanez, B. Conflitos Socioambientais, Ecologia Política e Justiça Ambiental: Contribuições para uma Análise Crítica. In: Anais do XI Encontro Nacional da ANPEGE. Presidente Prudente, 14 de jun., 2015.

Thomaz Júnior, A. O agrohidronegócio no centro das disputas territoriais e de classes no Brasil do século XXI. Campo-Território: Revista de Geografia Agrária, 5(10), 92-122, 2010. Disponível em: http://www.seer.ufu.br/index. $\mathrm{php} /$ campoterritorio/article/view/12042

Tôrres, M. A. História de água e minério: os efeitos do Projeto Minas-Rio em Água Quente, Conceição do Mato Dentro. Belo Horizonte, Monografia (bacharelado em Ciências Sociais) - UFMG, 2014.

Wanderley, M. N. "Franja Periférica", "Pobres do Campo", "Camponeses": dilemas da inclusão social dos pequenos agricultores familiares. In: Delgado, G. C.; Bergamasco, S. M. P. P. (Orgs.). Agricultura familiar brasileira: desafios e perspectivas de futuro. Brasília: Secretaria Especial de Agricultura e do Desenvolvimento Agrário, 2017. p. 64-81.

Wolf, E. Sociedades camponesas. Rio de Janeiro: Zahar, 1970.

Woortmann, K. Migração, família e campesinato. Revista Brasileira de Estudos de População, 7(1), 35-53, 1990. 
Disponível em: https://www.rebep.org.br/revista/article/ view/546

Woortmann, E. F. O saber tradicional camponês e inovações. In: Oliveira, A. U. de; Marques, M. I. M. (Org.). O campo no século XXI: território de vida, de luta e de construção social. São Paulo: Casa Amarela; Paz e Terra, 2004. p. 119-130.

Zhouri, A. Mineração e desregulação ambiental: Limites do consensualismo e da mediação em situações de conflito ambiental. In: Zhouri, A.; Valencio, N. (Orgs.). Formas de Matar, de Morrer e de Resistir: Limites da resolução negociada de conflitos ambientais. Belo Horizonte: Ed. UFMG, 2014. p. 111-142.

Zhouri, A.; Oliveira, R. Paisagens industriais e desterritorialização de populações locais: conflitos socioambientais em projetos hidrelétricos. In: Zhouri, A. (Org.). A insustentável leveza da política ambiental: desenvolvimento e conflitos socioambientais. Belo Horizonte: Autêntica, 2005. p. 49-64.

Zucarelli, M. C.; Santos, A. F. M. A desregulação ambiental e a dinâmica dos conflitos urbanos: o caso da mineração Minas-Rio. In: Anais ENANPUR. Belo Horizonte, 20 de mai., 2015. 